\title{
Movements causing ankle fractures in parachuting
}

\author{
N. Ellitsgaard and F. Warburg
}

Department of Orthopaedic Surgery, Bispebjerg University Hospital, Copenhagen, Denmark

\begin{abstract}
The parachutist injured in a dramatic accident often describes the injury in an incomplete and biased way and evaluation of materials based solely upon subjective information of this kind can be misleading and of no value for recommendations. As the relation between the mechanical factors of the injury and the lesion in ankle fractures is well documented, an investigation of clinical, radiological and operative findings in 46 parachutists with ankle fractures was conducted. Classification was possible in 44 of 46 fractures. The description of the cause of the trauma in 21 supination-eversion fractures and in 13 pronation-eversion fractures was most frequently faulty landing position or obstacles. The cause of seven supination fractures was oscillation of the parachutist whilst descending with sudden impact against the lateral aspect of the foot. For prophylaxis we recommend improvement of landing and steering techniques and the support of semi-calf boots.
\end{abstract}

Keywords: Parachuting, aviation, sports injury epidemiology

\section{Introduction}

Ankle fractures have been demonstrated in several studies to be the most common bony lesion in military as well as in sport parachuting ${ }^{1-4}$. The fractures occur during landing and are mainly caused by incorrect landing position or uneven landing ground. The subjective description of the injury may be incomplete due to the dramatic circumstances, and studies of such information subsequently do not provide a solid basis for recommendations. There are well-documented studies demonstrating the relationship between the prevailing forces and ankle fractures ${ }^{5-9}$.

The aim of the present study is to describe the mechanism of ankle fractures in parachutists by using a clinical-radiological classification. The results are compared with the parachutist's description of the trauma in order to discover a possible contradiction between subjective and objective data.

\section{Method}

From 1979 to 1983110000 parachute jumps were performed by members of the Danish Parachute Jumpers Association (DFU). One hundred and sixty-one jumps

Address for correspondence: Dr Niels Ellitsgaard, Kastelsvej 16, DK-2100 Copenhagen, Denmark

(C) 1989 Butterworth \& Co (Publishers) Ltd 0306-3674/89/010027-03\$03.00 resulted in casualties requiring medical treatment. Case records were obtained from the medical centres involved and revealed 46 ankle fractures in 46 parachutists. Radiographs were provided by the radiological departments concerned and the fractures were classified from the site of the fracture and the clinical or operative description of ligament injury. Subjective aetiology was drawn from the parachutists' report of the accident to the DFU as well as a supplementary questionnaire. These data were then compared to the classification obtained from the objective data. Morbidity for jumpers suffering ankle fractures was evaluated by the duration of hospital stay, sick leave and by the incidence of sequelae.

\section{Results}

Forty-four of 46 ankle fractures were classified according to the method of Lauge-Hansen (Table 1). The relationship of supination-eversion, pronation-eversion and supination-adduction fractures to the causes of injury stated by the jumper is listed in Table 2. For the 46 jumpers, the median hospital stay was six days (range 0 to 60 days). Median sick leave was 49 days (range 0 to 360 days). Twelve jumpers suffered sequelae after one year.

\section{Discussion}

The material consisted only of cases with radiologically verified fractures and did not incorporate injury to ligaments of the ankle joint in the absence of a fracture. Comparing the subjective descriptions of injury, we found none incompatible with the injuring forces deduced from the Lauge-Hansen classification which we regard as suitable for evaluation of ankle fractures following parachute jumps. The term 'improper landing attitude' (Table 2) most commonly means 'legs apart' and the resulting injury can occur as shown in Figure 1, the rear foot receiving an eversion force on contact with the ground. Minor irregularities in the ground or obstacles can force the foot into pronation or supination before the eversion occurs. As improper landing is the usual cause of both supination-eversion fractures and pronation-eversion fractures, eversion is the main aetiological factor in such fractures.

The main cause of supination-adduction fractures was registered as oscillation - an unintentional swinging of the parachutist under the canopy (Table 2). As a 
Movements causing ankle fractures in parachuting: N. Ellitsgaard and F. Warburg

Table 1. Classification of ankle fractures in parachuting

\begin{tabular}{llrrr}
\hline Supination-eversion: & grade & II & 4 & Total \\
& - & III & 4 & \\
& - & IV & 12 & \\
Supination-adduction: & grade & II & 7 & 21 \\
Pronation-eversion: & grade & II & 1 & 7 \\
& - & III & 4 & \\
& - & IV & 6 & \\
Pronation-adduction: & grade & III & 3 & 13 \\
Unclassified **: & & & & 3 \\
\hline Total & & & & 46 \\
\hline
\end{tabular}

* Grade 4 with talar luxation

** Fracture of posterior tibial margin

Table 2. Reported causes of trauma in eversion and supinationadduction fractures

\begin{tabular}{lccc}
\hline & $\begin{array}{c}\text { Supination- } \\
\text { eversion }\end{array}$ & $\begin{array}{c}\text { Pronation- } \\
\text { eversion }\end{array}$ & $\begin{array}{c}\text { Supination- } \\
\text { adduction }\end{array}$ \\
\hline Causes related to: & & & \\
Improper landing & 17 & 7 & 1 \\
attitude & 3 & 5 & 1 \\
Obstacles & 1 & 1 & 5 \\
Oscillation & 21 & 13 & 7 \\
\hline Total & & &
\end{tabular}

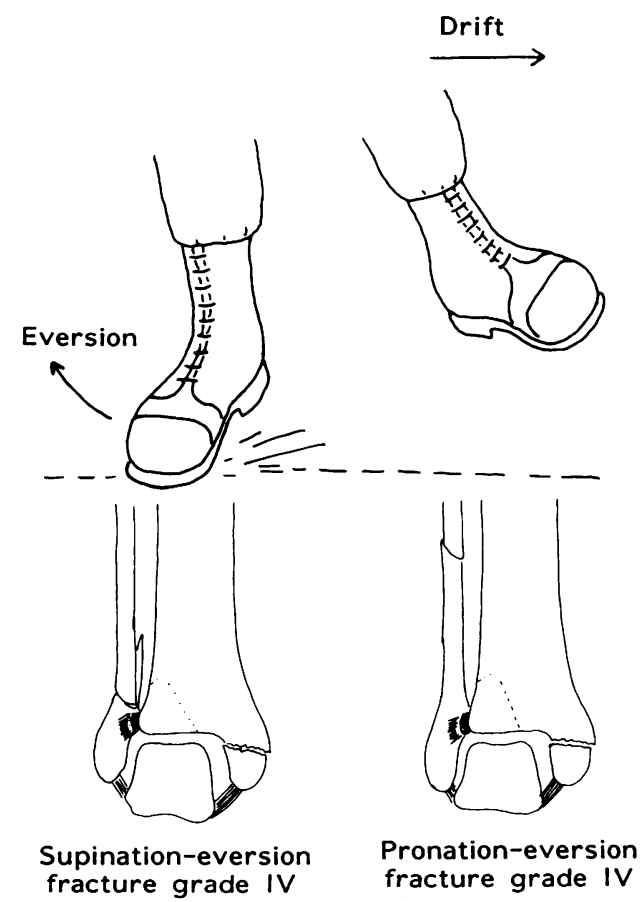

Figure 1. The mechanism of injury in eversion fractures. The effect of ground contact with legs apart

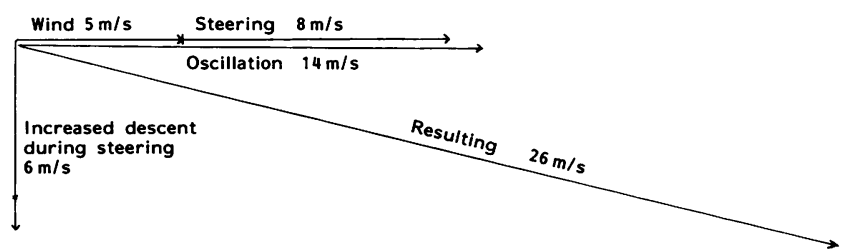

Figure 2. Calculated movement in the worst landing situation including maximum wind, faulty steering and a 90 degrees oscillation
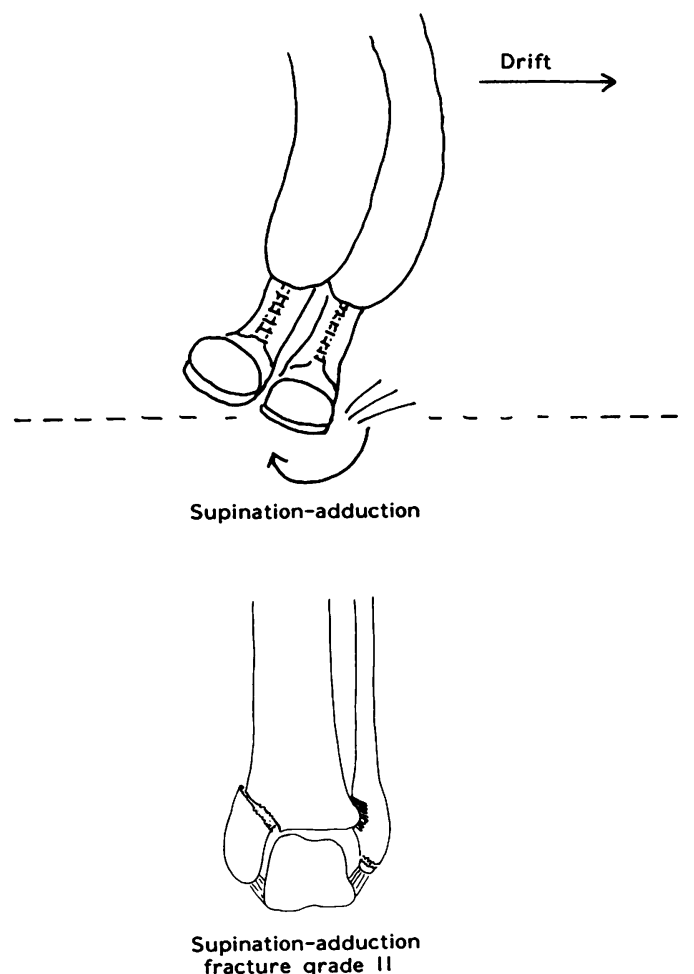

Figure 3. The mechanism of injury in supination-adduction fractures. The result of increased landing velocity

result, the increased kinetic energy following combined movements of descent, drift and oscillation exceed the energy absorbing capacity of the correctly slightly flexed semitense lower extremities. The outcome of canopy descent complicated by winddrift, faulty steering and oscillation is demonstrated in Figure 2 with the resulting movement of $26 \mathrm{~m} / \mathrm{s}$ equaling $55 \mathrm{miles} / \mathrm{h}$. Assuming that a correct landing position is taken up, the impact on the lateral margin of the forefoot will force it into supination, as shown in Figure 3.

The incidence of ankle fractures following sport parachute jumps and the accompanying loss of working days presents a significant problem. Sport jumping as a leisure occupation only justifies small risks and every effort to prevent injury should be introduced to reduce the present risk. The neglect of correct landing position represents mainly a problem to newcomers to the sport and as this can be reduced by simple ground level training, the value of practical pre-jump education should be stressed. A simplified landing technique eliminating error has recently been 
introduced ${ }^{4}$. The tendency in experienced jumpers, especially during competition, to violate basic methods of landing, thereby exceeding the laws of physics, should be recognized.

The demonstrated relationship between oscillation and supination-adduction lesions highlights the need to check the stability of the wind as well as the mean wind speed. Semi-calf boots might be valuable in reducing impact against the lateral aspect of the foot in situations of increased landing speed, and we suggest that such boots should be regarded as an obligatory prophylactic measure.

\section{References}

1 Davis, W.R. Parachuting injuries: Their prevention Milit Med 1964, 129, 1071-1076

2 Petras, A.F. and Hoffman, E.P. Roentgenographic skeletal injury patterns in parachute jumping $A m J$ Sports Med 1983, 11, 325-328

3 Amamilo, S.C., Samuel, A.W., Hesketh, K.T. and Moynihan, F.J. A prospective study of parachute injuries in civilians J Bone Jt Surg 1987, 69B, 17-19

4 Ellitsgaard N. Parachuting injuries: A study of 110,000 sports jumps Brit J Sports Med 1987, 21, 13-17

5 Lauge-Hansen, N. Fractures of the ankle: Analytic historic survey as the basis of new experimental, roentgenologic and clinical investigations Arch Surg 1948, 56, 259-317

6 Lauge-Hansen, N. Fractures of the ankle: Combined experimental-surgical and experimental-roentgenologic investigations Arch Surg 1950, 60, 947-985

7 Lauge-Hansen, N. Fractures of the ankle: Clinical use of genetic roentgen diagnosis and genetic reduction Arch Surg 1952, 64, 488-500

8 Lauge-Hansen, N. Fractures of the ankle: Genetic roentgenologic diagnosis of fractures of the ankle $A J R$ 1954, 71, 456-471

9 Arimoto, H.K. and Forrester, D.M. Classification of ankle fractures: An algorithm $A J R$ 1980, 135, 1057-1063 